\title{
Looking Beyond First-Person Effects (FPE) in the Influence of Scarcity Appeals in Advertising: A Replication and Extension of Eisend (2008)
}

\begin{abstract}
In this paper, we replicate and extend Eisend's (2008) pioneering work on first-person (FPE) effects in the context of scarcity appeals in advertising, using 'influence of presumed influence', a broader and less restrictive theoretical perspective compared to FPE to develop a revised conceptual model. Specifically, we hypothesize that it is the perceived influence on self and others, rather than the difference between them as hypothesized by Eisend (2008) that mediates the impact of value perception on purchase intention. Using a student sample similar to Eisend (2008) albeit with a different product category and advertising stimulus, we found that value perception has a direct positive effect on the perceived influence on others that affects the perceived influence on self, which in turn influences purchase intention. Besides offering an alternate model for future researchers to explore the role of scarcity appeals in advertising, our findings may also help advertisers focus on the perceived influence on others and use it to influence consumers' own value perceptions and purchase intentions.
\end{abstract}

Keywords: first-person effect, influence of presumed influence, purchase intention, scarcity appeals, third-person effect, value perception 


\section{INTRODUCTION}

Scarcity theory suggests that marketers can increase the perceived value of products and services by manipulating their perceived availability through promotions (Lynn 1991). Scarcity appeal is one of the most popular advertising appeals because consumers perceive scarce product to be desirable (Lee, Oh, and Jung 2014; Roy and Sharma 2015; Wu et al. 2012). As a result, marketers often use phrases such as, 'limited edition', 'nearly sold out due to high demand' or ' $80 \%$ of our stock already sold', to create perceived scarcity that may increase the demand for their products (Gierl and Huettl 2010) and products from cars to computer equipment and from fashion items and toys benefit from the use of scarcity appeals in advertising (Aggarwal, Jun, and Huh 2011; Aguirre-Rodriguez 2013).

'Third-person effect' (TPE) is a major theme in communication research according to which people generally believe that 'negative' messages have a greater effect on 'others' (i.e., third persons) than on 'self' (i.e., first-person) (Cohen, Mutz, Price, and Gunther 1988; Cohen and Davis 1991; Davison 1983; Gunther 1991; Perloff 1989; Xu and Gonzenbach 2008). Evidence of TPE in people's response to negative messages ranges from susceptibility to defamatory messages (Cohen et al. 1988), violent and misogynic rap lyrics (McLeod, Eveland, and Nathanson 1997), persuasive influence of media messages (Perloff 2002), pornography on the internet (Lee and Tamborini 2005; Wu and Koo 2001), alcohol product placements (Shin and Kim 2011) and sexual advertising (Pan, Meng, and Zhou 2012).

'First-person effect' (FPE) is a reversal of TPE in which people generally perceive a stronger influence of a 'positive' message on 'self' than on 'others' (Chapin 2000; Golan and Day 2008; Meirick 2005; White and Dillon 2000). However, the evidence about the role of TPE 
versus FPE in the positive advertising context is quite mixed, with some studies showing support for FPE (e.g., Eisend 2008; Gunther and Thorson 1992), some for TPE (Golan and Banning 2008; Huh, Delorme, and Reid 2004; Tal-Or 2007) or others for both TPE and FPE (Lo et al. 2015). Hence, there is still no consensus about the scope and boundaries of these effects.

In this context, Eisend's (2008) study makes an important contribution by showing the evidence of FPE in the context of scarcity appeals in advertising; wherein the difference between perceived influence on self and others mediates the impact of value perception on purchase intention. Eisend (2008) uses FPE to explain his findings and suggests that these may be driven by the mere 'perception of an influence' of the scarcity message rather than its actual influence. Interestingly, this idea is also in line with the 'Influence of presumed influence model' (IPI) model (Gunther and Storey 2003), which unlike TPE or FPE, focuses on the role of perceived influence on others rather than the difference in the perceived influence on self and others. Hence, it would be useful to reexamine Eisend's (2008) findings using the IPI model as an alternate theoretical perspective, to compare the direct roles of perceived influences on self and others rather than the difference between them as suggested by FPE.

IPI offers a broader framework about the influence of media on people irrespective of the message type (either positive or negative) and proposes TPE and FPE as its special conditions (Gunther and Storey 2003). Recent research supports the IPI model in advertising by showing that consumers perceive a stronger influence of advertising message on others than on self, which in turn affects their own attitudes and behaviors (Huh and Langteau 2007; Jiang and Chia 2009; Noguti and Russell 2014). Studies on scarcity appeals also show that consumers perceive being in competition with others to grab such offers and this may make them perceive a stronger effect of scarcity appeals on others, which in turn may shape their own attitudes and behaviors, 
referred to as 'herd mentality' underlying ‘bandwagon consumption' ((Aggarwal et al 2011;

Gierl and Huettl 2010; Van Herpen, Pieters, and Zeelenberg 2009).

In this paper, we address the conflicting findings about the impact of TPE and FPE in the positive advertising context by offering the IPI model as an alternate theoretical perspective to replicate and extend Eisend's (2008) work. Specifically, we posit two new hypotheses about the mediating roles of perceived influence on others and self (as suggested by IPI) rather than the difference between them (as suggested by FPE), in the process by which value perception resulting from a scarcity appeal affect purchase intentions. We use a different product category and manipulation of scarcity to answer Eisend's (2008) call for testing his original framework using a different stimulus. We also use different anchors for the multi-item measure for 'actual impact' than those used by Eisend (2008). In the next section, we briefly describe Eisend's (2008) study and then extend his model using the IPI perspective. We then describe our experimental study followed by a discussion of our findings and their contribution along with the limitations of our method and directions for future research.

\section{THEORETICAL BACKGROUND AND HYPOTHESES}

\section{Scarcity Appeal and Reversal of TPE (Eisend 2008)}

In his pioneering study Eisend (2008) argues that a scarcity appeal works like a positive message and should reverse the third-person effect because consumers may associate scarcity appeals with higher perceived value and believe that it is 'smart to be influenced' by the message. As a result they would overestimate the perceived influence of the message on self, as compared to others as well as its actual impact on self (Eisend 2008). In addition, the differential susceptibility between self versus others can act as a self-serving motivational bias and mediate 
the relationship between value perception and purchase intention (Eisend 2008). Based on these arguments, Eisend (2008) presented the following hypotheses:

H1: Value perception that is enhanced by scarcity appeals leads to (a) an increased perceived influence on self, relative to others, and (b) an increased perceived influence on self, relative to the actual impact.

H2: Perceived susceptibility mediates the relationship between value perception based on scarcity appeals and purchase intention, such as when an increased perceived influence on self, relative to others, leads to enhanced purchase intentions.

H3: Perceived susceptibility mediates the relationship between value perception based on scarcity appeals and purchase intention, such as when an increased perceived influence on self, relative to the actual impact, leads to enhanced purchase intentions.

Eisend (2008) tested these hypotheses by manipulating scarcity appeal using H \& M sunglasses endorsed by the designer Karl Lagerfeld in a fictitious advertisement. He informed the participants in the scarcity condition that 'limited supplies' of sunglasses were available for a 'short time'. In comparison, the non-scarcity condition specified 'sufficient items' in stock. Eisend (2008) found support for his $\mathrm{H} 1$ and H2, but not H3. These findings are in line with prior literature on FPE that shows a higher degree of influence on self than on others, especially in the case of positive media message, such as public service announcement (PSA) on AIDS prevention (Chapin 2000), organ donation (White and Dillon 2000) and even anti-smoking and seat belt safety campaigns (Meirick 2005). Studies also show evidence of FPE in case of positive advertising especially when the ads are emotional and pleasant (e.g., Gunther and Thorson 1992; David, Liu, and Myser, 2004; Wyllie, Zhang, and Casswell 1998). For example, Gunther and 
Thorson (1992) show that although ads with an emotional appeal equally affect self and others, participants tend to recognize and admit more of an impact on themselves in these positive situations. Similarly, others show that younger consumers may consider alcohol advertising as fun, youthful, exciting, and thus emotional, which creates a stronger perceived influence on them (i.e., FPE) compared to others (David et al. 2004; Wyllie et al., 1998).

\section{TPE versus FPE in Positive Advertising}

Notwithstanding the support for FPE in positive advertising and TPE in negative advertising messages in general (Cohen et al. 1988; Davison 1983; Perloff 1989, 1993), some studies show that TPE may also affect consumers for positive advertising messages (e.g., Golan and Banning 2008; Huh et al. 2004; Tal-Or 2007). For example, Golan and Banning (2008) show that advertisements (even from reputed brands such as Nike) are viewed as manipulative intent on behalf of companies, and hence even positive advertising messages may lead to negative consumer perception about the act of being persuaded by an advertisement. Similar findings are reported in the context of positive Direct-to-Consumers (DTC) advertising for prescription drugs (Huh et al. 2004) and energy bars (Tal-Or 2007).

Therefore, the findings about consumer response to positive advertising seem rather mixed as consumers perceive greater influence on others (TPE) in some cases and on self (FPE) in other cases. Meirick (2005) tries to reconcile this conflict by arguing that people may bolster their self-esteem by considering others to be relatively more vulnerable to the manipulative intent of positive advertising than themselves (TPE) or by claiming to be influenced by positive advertising to a greater extent compared to others in order to show themselves as being more pro-social and open minded (FPE). However, this perspective also focuses on the difference 
between the perceived influence on self and others and ignores the possibility that these may have their unique effects on the outcome variables (Gunther and Storey 2003).

\section{Influence of Presumed Influence}

We offer IPI model as a more parsimonious and less restrictive alternate theoretical perspective to address this conflict about both TPE and FPE being observed in the context of positive advertising, by removing the restrictive assumption associated with both TPE and FPE, namely 'message valence' and 'differential susceptibility'. Specifically, IPI considers consumer attitudes and behaviors to be affected through a perceived influence on a 'broader audience' rather than a direct influence on self or a differential impact of self versus others (Gunther and Storey 2003). IPI is also a more general concept, applicable to both positive and negative messages, with both TPE and FPE considered as its special cases (Gunther and Storey 2003).

Interestingly, Eisend (2008, p.37) hints that his findings are in line with the IPI perspective because it is the mere 'perception of an influence' and not the actual influence that may have caused the effects demonstrated in his study. However, he uses the 'differences between the perceived influences on self versus others' as the mediators in his model and does not consider 'impact of perceived influence on others' as the focal construct, as suggested by IPI model. In other words, according to IPI, it is the 'perceived influence on others' that should drive 'perceived influence on self', which in turn should affect the attitude and behavioral outcomes. Therefore, in this paper we use IPI as an alternate theoretical model to replicate and extend Eisend's (2008) research on the role of scarcity appeals in advertising.

Prior research also shows that scarcity appeals, especially when related to limited quantity, can have an influence on broader audience (Aggarwal et al. 2011; Gierl and Huettl 
2010; Van Herpen et al. 2009). A scarcity message can pitch buyers in competition with each other, as being able to take advantage of the restricted offer creates a sense of being 'smart buyers' amongst shoppers (Aggarwal et al. 2011). Specifically, Aggarwal et al (2011) show that a scarcity message can induce a competitive mindset amongst buyers, driven by which consumers want to grab the opportunity to purchase the scarce product. Similarly, other evidences show that scarcity appeal may indeed trigger off a herd mentality leading to bandwagon effect, with consumers preferring scarce products even more when others buy those (Gierl and Huettl 2010; Van Herpen et al. 2009). Based on the above, we hypothesize:

H4: Value perception that is enhanced by scarcity appeals leads to an increased perceived influence on (a) self, as well as (b) others.

As explained above, IPI is a more general framework and both TPE and FPE are its special cases (Gunther and Storey 2003). Moreover, IPI is applicable to both positive and negative messages; hence it helps resolve the mixed findings on the impact of TPE and FPE for positive advertisements. In fact, the whole notion of IPI rests on indirect media influences on the 'self' via the perceived influence on others, which makes it applicable to advertisements. For example, in the context of Direct-to-Consumer (DTC) advertising for pharmaceutical products, the physicians form perceptions about the influence of DTC advertising on their patients (others), which then influences their own (self) prescription behaviors (Huh and Langteau 2007). Similarly, in a study with Chinese college students, the perceived influence of advertisements on peers (others) is shown to affect own (self) materialistic attitudes (Jiang and Chia 2009). Noguti and Russell (2014) also show that the 'presumed influence' of TV series or product placements on acquaintances (others) affects consumers' own (self) attitudes and willingness to try a product. However, none of these studies explain the mechanism underlying this effect. 
We use prior research on the link between presumed influence on others and perceived influence on self (e.g., Park 2005) to argue that the presumed influence on others would positively affect the perceived influence on self, which in turn will have a positive influence on behavioral intentions. For example, in a study on the role of body images in mass media, Park (2005, p.604) shows that the presumed influence of a 'thin ideal' on others has a positive impact on its perceived influence on self $(\beta=0.46, p<.001)$, which in turn positively affects the participants' desire to be thin $(\beta=0.56, \mathrm{p}<.001)$. Based on this, we hypothesize as follows:

H5a: Perceived influence on others mediates the effect of value perception on perceived influence on self.

H5b: Perceived influence on self mediates the effect of perceived influence on others on purchase intention.

Figure 1 summarizes H1-H3 based on Eisend's (2008) model and figure 2 summarizes H4-H5 based on our extension of Eisend's (2008) model. Next, we describe the methodology used by us to test both these models followed by a discussion of our findings.

$<$ Insert Figures $1 \& 2$ about here $>$

\section{METHODOLOGY}

\section{Design and Sample}

One hundred and two undergraduates (57\% female; mean age 22.6 years) from an Australian university participated in an experiment with between-subjects design. This sample is similar to 
that used by Eisend (2008) with 114 undergraduate students in Germany (51.4\% female; mean age 23.5 years). Participants were randomly allocated to the experimental conditions.

\section{Stimuli and Procedure}

Following Eisend's (2008) advice to use different product categories to replicate his results, we chose mobile phones as the product category in this study based on their high visibility, similar to the sunglasses used by Eisend (2008), as reported in past research on scarcity appeals (e.g., Gierl and Huettl 2010). We used two print advertisements for Blackberry mobile phones to manipulate scarcity. In the scarcity condition the copy read 'Be bolder', 'Special edition Ice White Blackberry Bold 9700 Smartphone' along with a picture of the phone and an additional sentence 'Only 500 units available'. In the non-scarcity condition the copy simply stated 'Be bolder' and 'New Ice White Blackberry Bold 9700 Smartphone'. Both advertisements were otherwise identical in terms of copy layout, design and images. Participants were initially exposed to the advertisement, following which they completed the questionnaire that included the dependent variables, susceptibility measures, control and manipulation check variables. Finally, they reported their demographics (e.g., age and gender).

\section{Measures}

We measured the variable 'value perception' using the same semantic differential scale as Eisend (2008), with three adjective pairs as end-point anchors, namely 'very attractive/less attractive, desirable/undesirable, valuable/non-valuable' (Cronbach $\alpha=0.86$ ). Purchase intention was measured using a single seven point scale item 'How would you describe your willingness to buy the product' with 'definitely would not' and 'definitely would' as end points (Eisend 2008). The scarcity manipulation was checked with a single item by asking whether participants thought that 
there was limited opportunity to buy the product with 'strongly agree' and 'strongly disagree' as endpoints. The variable 'actual impact' (Bruner, Hensel, and James 2001) was measured with a semantic differential scale anchored by four adjectives pairs (mediocre/ exceptional, boring/exciting, unappealing/appealing and ordinary/unique) (Cronbach $\alpha=0.82)$. Although these items are different from those used by Eisend (2008) (bad/good, unpleasant/pleasant, inferior/superior, negative/positive), they still tap the same construct (i.e., acceptance of the advertised brand) conceptualized by Eisend (2008).

Susceptibility measures were taken from Eisend (2008) and for the perceived influence on self, the following questions were asked: 'How much do you think this advertising has affected your attitude toward the products? Has it made it more negative or more positive?' Participants were also asked how much they thought the information had affected the opinions of other consumers towards the product in the advertisement, anchored on a seven point scale with 'more negatively' and 'more positively' as end points. The difference between both measures was used to compute perceived susceptibility; a positive value means participants perceived higher influence on others relative to self. Similarly a negative value would indicate higher perceived influence on the self as compared to others. A difference was also computed between the perceived and the actual impact, with positive values indicating participants perceiving lower impact on self, compared to the actual, while negative values indicated higher influence on the self, relative to the actual (Eisend 2008).

A number of control variables were also included in the study following Eisend (2008). First, involvement was measured by how much participants agreed/ disagreed with the following statement on a seven point scale: 'This is a product that interests me', 'I have purchased products from the category before', 'This product type helps me attain the type of life I strive for', 'This 
product type has a high personal value for me', 'This is a product I could talk about for a long time' (Cronbach $\alpha=.77)$. Further, 'persuasive intention' was measured with two seven point scale items by asking participants how they perceived the company's motive to be with endpoints such as, 'not self-interested/highly self-interested', and 'strong profit motive/ minor profit motive' (Cronbach $\alpha=0.69$ ).

\section{DATA ANALYSIS AND RESULTS}

We began our data analysis by checking the manipulation of scarcity using the same method as Eisend (2008) and found that the ad with non-scarcity appeal shows a significantly higher perceived product availability compared to the other ad $\left(\mathrm{M}_{\text {scarcity }}=4.38\right.$ versus $\mathrm{M}_{\text {nonscarcity }}$ $=5.37 ; F=9.40 ; p<.01)$, as expected. Similar to Eisend $(2008)$, we found no difference for perceived persuasive intention $\left(\mathrm{M}_{\text {scarcity }}=4.85\right.$ versus $\left.\mathrm{M}_{\text {nonscarcity }}=4.81 ; \mathrm{F}=0.39 ; \mathrm{p}>.84\right)$ or involvement $\left(\mathrm{M}_{\text {scarcity }}=3.93\right.$ versus $\left.\mathrm{M}_{\text {nonscarcity }}=4.20 ; \mathrm{F}=1.17 ; \mathrm{p}>.28\right)$ between the two ads. In addition, we also compared the two experimental groups for other variables, including attitudes towards the product and the brand as well as demographics (age, gender and ethnicity) and found no significant differences. Hence, our findings are not confounded by any of these variables. Table 1 shows the correlations matrix for the variables included in our conceptual model.

$<$ Insert Table 1 about here $>$

We used a structural model (Model 1) to test H1-H3. Model 1 shows a close fit $\left(\chi^{2}=\right.$ 24.93, $\left.\mathrm{df}=23, \chi^{2} / \mathrm{df}=1.08 ; \mathrm{GFI}=.95, \mathrm{CFI}=.99, \mathrm{RMSEA}=.029, \mathrm{SRMR}=.058\right)$ with all fit indices better than the recommended cut-off values. The results show that scarcity appeal has a significant positive impact on value perception $(\beta=.31, p<.01)$ but value perception has no significant effect on either perceived influence on self, relative to the others (H1a: $\beta=.06, p>$ 
$.59)$ or perceived influence on self, relative to the actual impact (H1b: $\beta=-.06, p>.55)$, thus $\mathrm{H} 1 \mathrm{a}$ and $\mathrm{H} 1 \mathrm{~b}$ are not supported. Moreover, neither perceived influence on self, relative to others $(\beta=.11, p>.25)$ nor relative to the actual impact $(\beta=-.11, p>.28)$ have a significant effect on purchase intention. In view of these non-significant results, we did not test for the mediating role of perceived susceptibility and concluded that $\mathrm{H} 2$ and $\mathrm{H} 3$ are also not supported.

Next, we used Model 2 to test H4-H5. Model 2 also shows a close fit $\left(\chi^{2}=30.40, \mathrm{df}=24\right.$, $\left.\chi^{2} / \mathrm{df}=1.27 ; \mathrm{GFI}=.93, \mathrm{CFI}=.98, \mathrm{RMSEA}=.051, \mathrm{SRMR}=.071\right)$ with all the fit indices better than the recommended cut-off values. Once again scarcity appeal has a significant positive effect on value perception $(\beta=.33, \mathrm{p}<.001)$, while value perception has a significantly stronger effect on perceived influence on others (H4b: $\beta=.56, p<.001)$ than on self $(\mathrm{H} 4 \mathrm{a}: \beta=.34, \mathrm{p}<.001)$, thus $\mathrm{H} 4 \mathrm{a}$ and $\mathrm{H} 4 \mathrm{~b}$ are supported. Moreover, perceived influence on others has a significant effect on self $(\mathrm{H} 5 \mathrm{a}: \beta=.35, \mathrm{p}<.001)$ and perceived influence on self has a significant effect on purchase intentions (H5b: $\beta=.14, \mathrm{p}<.05)$.

Finally, we used Eisend's (2008) method to test the mediating role of perceived influence on others and on self, by comparing the path coefficients of the unconstrained model 2 with two constrained models in which the path coefficients for the two mediating effects were set to zero respectively (Shrout and Bolger 2002). The first constrained model shows a significantly poorer fit $\left(\chi^{2}=78.95, \mathrm{df}=26, \chi^{2} / \mathrm{df}=3.05 ; \mathrm{GFI}=.87, \mathrm{CFI}=.87, \mathrm{RMSEA}=.142, \mathrm{SRMR}=.185\right)$ compared to the unconstrained model $\left(\Delta \chi^{2}=48.55, \Delta \mathrm{df}=2, \mathrm{p}<.001\right)$, thus perceived influence on others mediates the effect of value perception on perceived influence on self, supporting H5a. Next, the second constrained model also shows a poorer fit $\left(\chi^{2}=43.36, \mathrm{df}=26, \chi^{2} / \mathrm{df}=1.67\right.$; $\mathrm{GFI}=.91, \mathrm{CFI}=.95, \mathrm{RMSEA}=.081, \mathrm{SRMR}=.098)$ compared to the unconstrained model $\left(\Delta \chi^{2}\right.$ 
$=12.96, \Delta \mathrm{df}=2, \mathrm{p}<.001)$, which shows that the perceived influence on self mediates the impact of perceived influence of others on purchase intention. Hence, H5b is also supported.

\section{GENERAL DISCUSSION}

In this paper, we describe our efforts to replicate and extend Eisend's (2008) research on the mediating role of FPE in the impact of scarcity appeals in advertising on consumers' purchase intentions. We used a student sample similar to Eisend (2008) albeit with a different product category (mobile phones) to validate and test the generalizability of his model. We also added two new hypotheses based on IPI model (a less restrictive model and a broader generalization of the TPE and FPE) combined with recent findings from the scarcity literature. Specifically, we hypothesize that the consumers' value perception triggered by scarcity appeals will have an influence on both self (H4a) and others (H4b); and perceived influence on others will drive perceived influence on self (H5a), which in turn will affect purchase intention (H5b).

The results from our path analysis (Model 1) only support that scarcity appeal has a direct influence on value perception (Lynn 1992), a finding also supported by Eisend's (2008) research. Notably in his original research Eisend (2008) also did not find support for all his hypotheses, with only two out of three original hypotheses being supported. In fact, we could not replicate any of Eisend's (2008) hypotheses, with no significant results for the influence of value perception on the difference between perceived influence on self versus others (H1a) or perceived versus actual influence on self $(\mathrm{H} 1 \mathrm{~b})$ and no support for the mediating role of the difference between perceived influence on self versus others (H2) or perceived versus actual influence on self $(\mathrm{H} 3)$ on the effect of value perception on purchase intention. In contrast, we found full support for our revised model (Model 2) and new hypotheses (H4 and H5). 
Specifically, our findings show that value perception driven by scarcity appeal have an impact on perceived influence on self and others but they may not drive the difference in these two perceived influences. However, in line with IPI model, we did find that the impact of value perception on perceived influence on others may be a bit stronger than the perceived influence on self. Finally, value perception's influence on others has an influence on the self, which in turn leads to purchase intention. All our findings are aligned with the less restrictive IPI model and show that scarcity appeal acts by having a broader influence on the audience (i.e. influence on others). This influence possibly triggers off a competition amongst the buyers, which then has an influence on the individual (i.e. self) because it may promote a herd mentality and encourage bandwagon behaviour (Aggarwal et al. 2011; Van Herpen et al. 2009).

\section{LIMITATIONS AND FUTURE RESEARCH}

In this study we could not replicate Eisend's (2008) findings but we found full support for our revised model. We explain the main reason for these differences based on our use of the IPI model, which is broader and less restrictive compared to the TPE/FPE model used by Eisend (2008). However, there are some operational issues that may have also affected our results.

First, we used a single-item measure for 'perceived susceptibility' similar to Eisend (2008) but such single-item scales can be problematic due to their low reliability and this may have partly led to the differences in our results. Similarly, our measure of 'actual impact' also uses conceptual anchors similar to 'perceived influence on self', a limitation also mentioned by Eisend (2008). Future studies may address these limitations by using a multi-item scale for 'perceived susceptibility' and different conceptual anchor for 'actual impact' in comparison to 
'perceived influence on self' construct. They could also measure the 'actual impact' construct as the participants' acceptance of the advertised brand in a pre- and post-exposure to the stimulus.

Second, we operationalize scarcity appeal only through 'limited quantity', while Eisend (2008) uses a mix of limited quantity and time, which may have also led to the differences in our findings. Specifically, Eisend's (2008) advertising stimulus was based on the huge success of the designer Karl Lagerfeld in real life that may have reminded participants of how his apparel collection had run out quickly in the past. Given the popularity of the product lines from this designer in real life, it is possible that consumers could have experienced positive emotions, which could have triggered off the FPE (Gunther and Thorson 1992). Alternatively, participants may have found Eisend's (2008) stimulus as more convincing, similar to a strong argument that led to FPE (Lo et al. 2015). Future research may overcome these limitations by using stronger manipulation of scarcity appeals in advertising and possibly by exploring the differences in the impact of limited quantity versus limited time. 


\section{REFERENCES}

Aggarwal, Praveen, Sung Youl Jun, and Jong Ho Huh (2011), "Scarcity messages," Journal of Advertising, 40 (3), 19-30.

Aguirre-Rodriguez, Alexandra (2013), "The Effect of Consumer Persuasion Knowledge on Scarcity Appeal Persuasiveness," Journal of Advertising, 42 (4), 371-79.

Bruner, Gordon C., Paul J. Hensel, and Karen E. James (2001), Marketing scales handbook. Chicago, IL: American Marketing Association.

Chapin, John R. (2000), "Not like me: Self vs. other distinctions in first-person perception," Communication Research Reports, 17 (3), 320-30.

Cohen, Jeremy and Robert G. Davis (1991), "Third-person effects and the differential impact in negative political advertising," Journalism \& Mass Communication Quarterly, 68 (4), 680-88.

Cohen, Jeremy, Diana Mutz, Vincent Price, and Albert Gunther (1988), "Perceived impact of defamation an experiment on third-person effects," Public Opinion Quarterly, 52 (2), 161-73.

David, Prabu, Kaiya Liu, and Michael Myser (2004), "Methodological artifact or persistent bias? Testing the robustness of the third-person and reverse third-person effects for alcohol messages," Communication Research, 31 (2), 206-233.

Davison, W. Phillips (1983), "The third-person effect in communication," Public opinion quarterly, 47 (1), 1-15.

Eisend, Martin (2008), "Explaining the impact of scarcity appeals in advertising: The mediating role of perceptions of susceptibility," Journal of Advertising, 37 (3), 33-40.

Gierl, Heribert and Verena Huettl (2010), "Are scarce products always more attractive? The interaction of different types of scarcity signals with products' suitability for conspicuous consumption," International Journal of Research in Marketing, 27 (3), 225-35.

Golan, Guy J. and Stephen A. Banning (2008), "Exploring a link between the third-person effect and the theory of reasoned action: Beneficial ads and social expectations," American Behavioral Scientist.

Golan, Guy J. and Anita G. Day (2008), "The first-person effect and its behavioral consequences: A new trend in the twenty-five year history of third-person effect research," Mass Communication and Society, 11 (4), 539-56.

Gunther, Albert (1991), "What we think others think: Cause and consequence in the third-person effect," Communication Research, 18 (3), 355-72.

Gunther, Albert C. and J. Douglas Storey (2003), "The influence of presumed influence," Journal of Communication, 53 (2), 199-215. 
Gunther, Albert C. and Esther Thorson (1992), "Perceived persuasive effects of product commercials and public service announcements third-person effects in new domains," Communication Research, 19 (5), 574-96.

Huh, Jisu, Denise E. Delorme, and Leonard N. Reid (2004), "The third-person effect and its influence on behavioral outcomes in a product advertising context: The case of direct-toconsumer prescription drug advertising," Communication Research, 31 (5), 568-99.

Huh, Jisu and Rita Langteau (2007), "Presumed influence of DTC prescription drug advertising: Do experts and novices think differently?," Communication Research, 34 (1), 25-52.

Jiang, Ranxi and Stella C. Chia (2009), "The direct and indirect effects of advertising on materialism of college students in China," Asian Journal of Communication, 19 (3), 319-336.

Lee, Byoungkwan and Ron Tamborini (2005), "Third-Person Effect and Internet Pornography: The Influence of Collectivism and Internet Self-Efficacy," Journal of Communication, 55 (2), 292-310.

Lee, Seung Yun, Sangdo Oh, and Sunho Jung (2014), "The effects of scarcity appeal on product evaluation: Consumers' cognitive resources and company reputation," Social Behavior and Personality: an international journal, 42 (5), 743-56.

Lo, Ven-hwei, Ran Wei, Hung-Yi Lu, and Hsin-Ya Hou (2015), "Perceived Issue Importance, Information Processing, and Third-Person Effect of News about the Imported US Beef Controversy," International Journal of Public Opinion Research, 1-20.

Lynn, Michael (1992), "The psychology of unavailability: Explaining scarcity and cost effects on value," Basic and Applied Social Psychology, 13 (1), 3-7.

(1991), "Scarcity effects on value: A quantitative review of the commodity theory literature," Psychology \& Marketing, 8 (1), 43-57.

McLeod, Douglas M., William P. Eveland, and Amy I. Nathanson (1997), "Support for censorship of violent and misogynic rap lyrics an analysis of the third-person effect," Communication Research, 24 (2), 153-74.

Meirick, Patrick C. (2005), "Rethinking the Target corollary the effects of social distance, perceived exposure, and perceived predispositions on first-person and third-person perceptions," Communication Research, 32 (6), 822-43.

Noguti, Valeria and Cristel Antonia Russell (2014), "Normative influences on product placement effects: Alcohol brands in television series and the influence of presumed influence," Journal of Advertising, 43 (1), 46-62.

Pan, Po-Lin, Juan Meng, and Shuhua Zhou (2012), "Examining third-person perceptions in the context of sexually oriented advertising," Journal of Promotion Management, 18 (2), 189-208. 
Park, Sung-Yeon (2005), “The Influence of Presumed Media influence on Women's Desire to be Thin," Communication Research, 32 (5), 594-614.

Perloff, Richard M. (1989), "Ego-involvement and the third person effect of televised news coverage," Communication research, 16 (2), 236-62.

(1993), "Third-person effect research 1983-1992: A review and synthesis," International Journal of Public Opinion Research, 5 (2), 167-84.

----- (2002), "The third-person effect," in Media effects: Advances in theory and research, Jennings Bryant and Dolf Zillmann, eds. New Jersey: Lawrence Erlbaum, 489-506.

Roy, Rajat and Piyush Sharma (2015), "Scarcity Appeal in Advertising: Exploring the Moderating Roles of Need for Uniqueness and Message Framing," Journal of Advertising, published online 20 March 2015, DOI:10.1080/00913367.2015.1018459.

Shin, Dong-Hee and Jun Kyo Kim (2011), "Alcohol product placements and the third-person effect," Television \& New Media, 12 (5), 412-40.

Shrout, Patrick E. and Niall Bolger (2002), "Mediation in Experimental and Nonexperimental Studies: New Procedures and Recommendations," Psychological Methods, 7 (4), 422-45.

Tal-Or, Nurit (2007), "Age and third-person perception in response to positive product advertisements," Mass Communication \& Society, 10 (4), 403-22.

Van Herpen, Erica, Rik Pieters, and Marcel Zeelenberg (2009), "When demand accelerates demand: Trailing the bandwagon," Journal of Consumer Psychology, 19 (3), 302-312.

White, H. Allen and John F. Dillon (2000), "Knowledge about others' reaction to a public service announcement: The impact on self persuasion and third-person perception," Journalism \& Mass communication quarterly, 77 (4), 788-803.

Wu, Wei and Soh Hoon Koo (2001), "Perceived effects of sexually explicit Internet content: The third-person effect in Singapore," Journalism \& Mass Communication Quarterly, 78 (2), 260-74.

Wu, Wann-Yih, Hsiao-Yun Lu, Ying-Yin Wu, and Chen-Su Fu (2012), "The effects of product scarcity and consumers' need for uniqueness on purchase intention," International journal of consumer studies, 36 (3), 263-74.

Wyllie, Allan, Jia Fang Zhang, and Sally Casswell (1998), "Responses to televised alcohol advertisements associated with drinking behaviour of 10-17-year-olds," Addiction, 93 (3), 361371.

$\mathrm{Xu}$, Jie and William J. Gonzenbach (2008), "Does a perceptual discrepancy lead to action? A meta-analysis of the behavioral component of the third-person effect," International Journal of Public Opinion Research, 20 (3), 375-85. 


\section{FIGURE 1}

Original Conceptual Framework (Eisend 2008) - Model 1

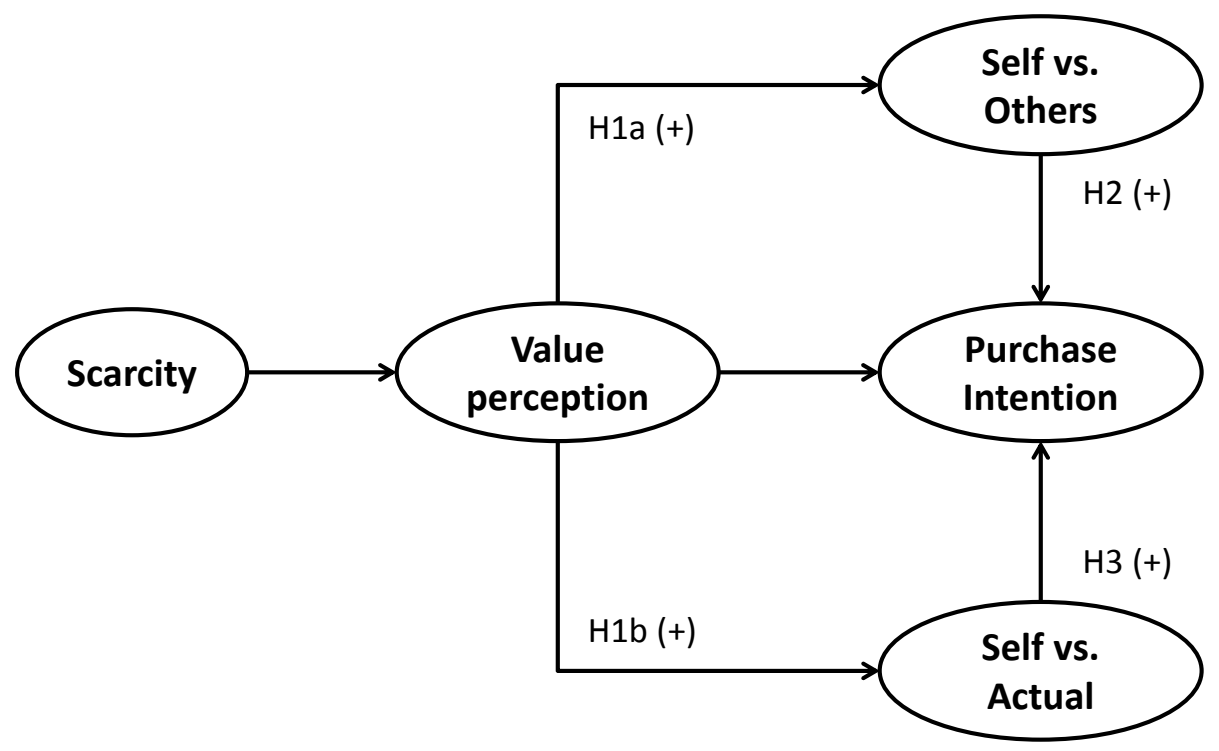


FIGURE 2

Revised Conceptual Framework (Model 2)

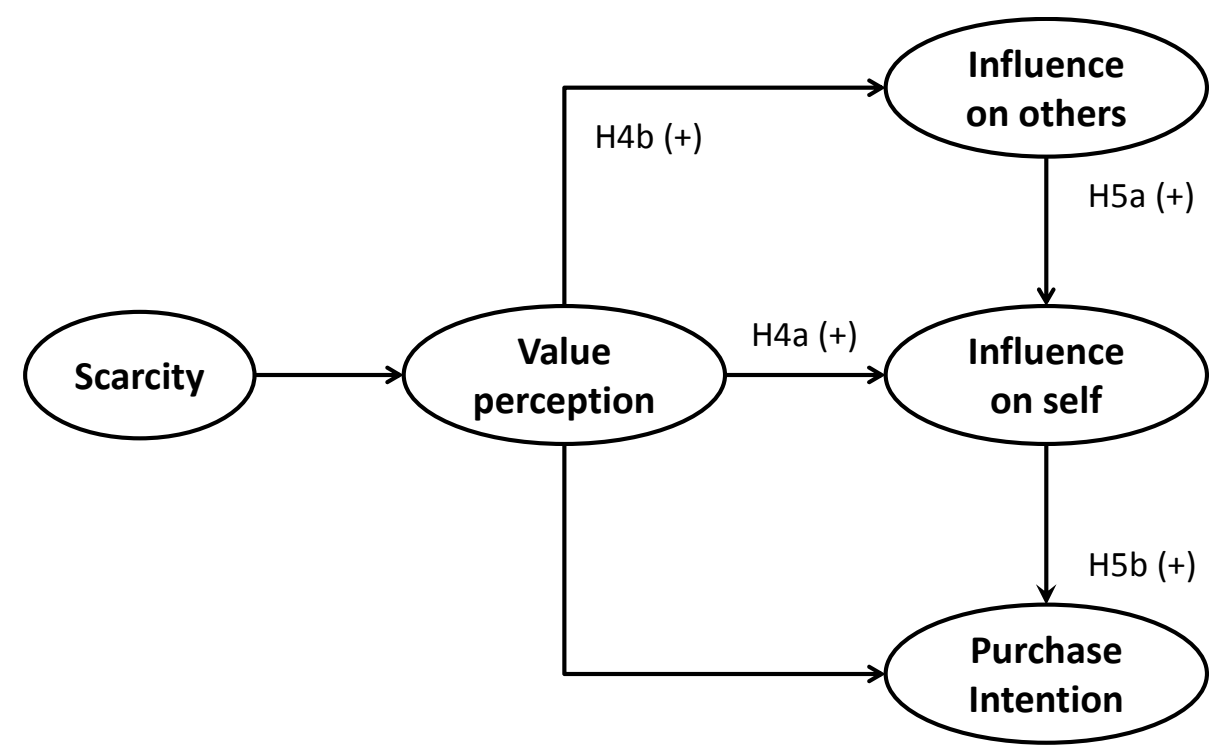


TABLE 1

Correlations

\begin{tabular}{|l|c|c|c|c|c|c|c|c|c|}
\hline & $\mathrm{M}$ & $\mathrm{SD}$ & $\mathrm{SC}$ & $\mathrm{VP}$ & $\mathrm{IS}$ & $\mathrm{IO}$ & SO & SA & PI \\
\hline Scarcity (SC) & 4.86 & 1.41 & 1.00 & & & & & & \\
\hline Value Perception (VP) & 4.60 & 1.13 & $.29^{* *}$ & 1.00 & & & & & \\
\hline Influence on Self (IS) & 4.59 & 1.09 & $.22^{*}$ & $.53^{* *}$ & 1.00 & & & & \\
\hline Influence on Others (IO) & 4.74 & 0.95 & $.40^{* *}$ & $.54^{* *}$ & $.54^{* *}$ & 1.00 & & & \\
\hline Self vs. Others (SO) & -0.14 & 0.98 & -.14 & .06 & $.58^{* *}$ & $-.37^{* *}$ & 1.00 & & \\
\hline Self vs. Actual (SA) & 0.15 & 1.02 & .04 & -.08 & $.51^{* *}$ & .17 & $.40^{* *}$ & 1.00 & \\
\hline Purchase Intention (PI) & 3.70 & 1.45 & .08 & $.43^{* *}$ & $.35^{* *}$ & $.31^{* *}$ & .10 & -.09 & 1.00 \\
\hline
\end{tabular}

$\mathrm{M}=$ Mean; $\mathrm{SD}=$ Standard Deviation 